\title{
How Dirty Teeth and Tongues are Killing our Geriatric Population Sonya Dunbar, RDH, BSDH
}

\author{
Mobile Dental Xpress Wellness and Nutrition, USA.
}

geriatrictoothfairy@800mdx.com

*Corresponding Author: Sonya Dunbar, RDH, BSDH, Mobile Dental Xpress Wellness and Nutrition, USA.

\begin{abstract}
In my 15 plus years working as a dental hygienist in long term care facilities, I have seen the most reprehensible oral care imaginable. I have witnessed dentures that had not been removed or cleaned in years. I have seen tube-fed residents who had not had their teeth brushed in months because of the staff's failure to see the necessity of providing oral homecare. I recently treated a patient who had so much tartar build up on his lower anterior teeth that he could not close his mouth or properly chew his food. I have listened to the countless, heart-wrenching accounts of elders so embarrassed by their dental condition that they were ashamed to smile or even let me examine their mouths. Dental health plays a significant role in mental and emotional health and well-being. Therefore, caregiver provision of proper oral homecare helps maintain the dignity of the geriatric community. Whether the neglect is due to caregivers' lack of knowledge or lack of compassion, the result is detrimental to the systemic health of the elderly. Uncontrolled oral bacteria can lead to pneumonia, diabetes, strokes, and heart attacks. It has even been linked to Alzheimer's Disease. Frequently, cognitive impairment intensifies preexisting oral problems. For instance, elders with Alzheimer's typically have poor oral care and a higher incidence of oral diseases. The most deplorable aspect of this situation is the fact that it is readily preventable. The quality of life and systemic health of residents in long term care facilities can be significantly improved by simple, consistent, and effective oral care practices.
\end{abstract}

\section{INTRODUCTION}

Many residents of long term care facilities have poor oral hygiene due to lack of professional oral health care. Eighty percent of residents do not receive daily oral care despite the fact that $94 \%$ of residents who wear dentures cannot properly clean them, and $84 \%$ of residents cannot brush their own teeth.

This is a serious matter because of the relationship between aspiration pneumonia and poor oral care. Pneumonia is the most common cause of infectious death among nursing home residents. Inhalation of the bacteria on the teeth and tongue can be deadly to a nursing home resident. (Yoneyama et al. 1999, 2002)

In addition, the use of medication such as antihistamines, decongestants, diuretics, painkillers, and antidepressants can reduce salivary flow. Saliva washes away food and neutralizes acids produced by bacteria in the mouth, helping to protect the oral cavity. Insufficient saliva can result in microbial invasion or overgrowth, leading to oral diseases and the inability to perform adequate oral hygiene.

\section{METHODOLOGY}

Many consider tooth brushing to be the best standard of oral care. (Stein \& Henry, 2009) Dental professionals recommend that teeth should be brushed for two minutes twice daily. Therefore, it is shocking that the average time spent brushing residents' teeth in longterm care facilities was only 16.2 seconds per session (Coleman \& Watson, 2006). Most nursing aids use sponge swabs not toothbrushes, but a swab does not remove plaque as effectively as a toothbrush (Pace \& McCullough, 2010). Insufficient education for staff also contributes to poor oral care (Stein \& Henry, 2009). All these factors contribute to increased bacteria in the mouth, which is linked to oral and systemic diseases.

In long term care facilities pneumonia accounts for 13 to $48 \%$ of all infections and is the leading cause of death in residents aged 65 years and older(El- 
Solh 2011) Death rates vary from 1 to $48 \%$ and are associated with age, comorbidities, and the severity of the disease (Welte et al. 2012). Clinically, residents feel sick and present with cough, purulent sputum, fever, sweats, pain, and suffocation hazard. Very old residents lack these classic symptoms and rather present with disorientation and some may even fall (Janssens and Krause 2004).

Silent aspiration of treacherous oral microorganisms resulting from poor oral hygiene is a major contributing factor to nursing home pneumonia. It can be found in places we would never suspect. There is evidence for the first time that denture wearing during sleep doubles the risk of pneumonia in very old people (Iinuma et al. 2014). Microorganisms of denture plaque associated with periodontal disease were found in the lungs of patients who were denture wearers. (Imsand et al. 2002).

The tongue is another place that harmful oral microorganisms populate. A study was conducted on seventy-one edentulous residents of long term care facilities age 65 years and older. The study evaluated the quantity of tongue-coating and found that elderly residents whose tongues were coated had "significantly higher salivary bacterial counts" than those whose tongues were not coated. The study also revealed that the risk of developing pneumonia was higher for elderly patients with poor oral hygiene, "suggesting that tongue-coating is a risk indicator of aspiration pneumonia in edentate subjects."(Abe et al. 2008).

\section{Discussion}

Poor oral care is directly linked to many systemic diseases such as Endocarditis which is an infection of the inner lining of the heart. When there is poor oral hygiene, the bacteria then spread through the bloodstream and attach to damaged areas of the heart. Some studies have shown that oral bacteria can travel through the bloodstream and elevate C-reactive protein, a marker for inflammation in blood vessels.
This can increase the risk of cardiovascular disease and stroke. Poor oral hygiene has even been linked to Alzheimer's Disease. The bacteria Porphyromonas gingivalis, which is usually associated with chronic gum disease, has been found in the brain of patients with Alzheimer Disease.

\section{ConClusion}

Limited oral care for residents of long term care facilities can lead to pain and infections from oral disease that could have been prevented. It can also lead to unnecessary health conditions and premature death. Proper education is needed for caregivers of the geriatric population. Until we establish routine oral care to residents of long term care facilities, we will continue to lose our greatest generation.

\section{REFERENCES}

[1] Abe S, Ishihara K, Adachi M, Okuda K. 2008. Tonguecoating as risk indicator for aspiration pneumonia in edentate elderly. Arch Gerontol Geriatr. 47:267275. [PubMed]

[2] El-Solh AA. 2011. Association between pneumonia and oral care in nursing home residents. Lung. 189:173-180. [PubMed]

[3] Janssens JP, Krause KH. 2004. Pneumonia in the very old. Lancet Infect Dis. 4:112-124. [PubMed]

[4] Iinuma T, Arai Y, Abe Y, Takayama M, Fukumoto M, Fukui Y, et al. 2014. Denture wearing during sleep doubles the risk of pneumonia in the very elderly. J Dent Res. doi:10.1177/0022034514552493 [PMC free article] [PubMed] [Cross Ref]

[5] Welte T, Torres A, Nathwani D. 2012. Clinical and economic burden of community-acquired pneumonia among adults in Europe. Thorax. 67:71-79. [PubMed]

[6] Yoneyama T, Yoshida M, Ohrui T, Mukaiyama H, Okamoto H, Hoshiba K, et al. 2002. Oral care reduces pneumonia in older patients in nursing homes. J Am Geriatr Soc. 50:430-433. [PubMed\}

Citation: Sonya Dunbar. How Dirty Teeth and Tongues are Killing our Geriatric Population. Open Journal of Geriatrics. 2018; 1(1): 31-32.

Copyright: (C) 2018 Sonya Dunbar. This is an open access article distributed under the Creative Commons Attribution License, which permits unrestricted use, distribution, and reproduction in any medium, provided the original work is properly cited. 